\title{
Odontogenic Myxoma of the Maxilla Infiltrating the Maxillary Sinus: A Rare Case Report
}

\author{
Dr. Sheeba $\mathrm{Ali}^{1}$, Dr. Puja Bansal ${ }^{2}$, Dr. Deepak Bhargava ${ }^{3}$, Dr. Vandheer Kunal ${ }^{4}$ \\ ${ }^{1}$ Post Graduate Student, ${ }^{2}$ Reader, ${ }^{3}$ HOD \& Professor, ${ }^{4}$ Post graduate Student \\ Department of Oral Pathology \& Microbiology, School of Dental Sciences, Sharda University, Greater Noida
}

\begin{abstract}
Odontogenic myxomas are tumors derived from embryonic mesenchymal elements of dental anlage. Although benign, odontogenic myxomas draw great attention because of their invasive nature into the surrounding tissues, which make the tumour amenable to recur especially after conservative treatment. We present a case of odontogenic myxoma with a displaced maxillary molar in the sinus, an unusual radiographic finding reported in literature.
\end{abstract}

Key words: Odontogenic, Myxoma, Mesenchymal, Tumor, Benign

\section{Introduction}

Odontogenic myxoma (OM) is an uncommon, mucoid neoplasm of oral cavity. As it resembles the dental pulp microscopically ${ }^{1}$, in 2003, the World Health Organization (WHO) classified it as a benign neoplasm arising from odontogenic ectomesenchyme with or without odontogenic epithelium ${ }^{2}$, ultrastructural features suggesting many lesional cells to be very similar to fibroblast and myofibroblasts. ${ }^{1}$ It is regarded as a locally invasive tumour displaying aggressive infiltration, that does not metastasize and exhibits slow and asymptomatic expansion, sometimes resulting in perforation of the cortical borders of the affected bone. ${ }^{3,4}$

The radiographic appearance of odontogenic myxoma of the jaws varies considerably. Large lesions may exhibit characteristic radiological signs of a slowly growing lesion. However, discrete displacement of teeth associated with a small osteolytic zone of the alveolar process between two teeth can be an OM. Careful interpretation of conventional radiographs is a must in identifying early lesions. ${ }^{5}$

The tumor is rich in extracellular matrix (ECM) represented by type I collagen, fibronectin, tenasin, chondroitin sulfate and especially abundant hyaluronic acid. This excessive ECM production has been implicated in the invasive behavior of the tumor. However, the exact mechanism involved in the local invasiveness of the tumor have not been established yet. ${ }^{6}$

In view of its rarity, a case of odontogenic myxoma of the maxilla infiltrating the maxillary antrum and adjacent tissues is herewith reported.

\section{Case report}

A 24 year old female patient reported with a chief complaint of painless, gradually progressive swelling in upper left side of face since one and half years. There was no history of trauma. Past medical and dental histories were non-contributory to the swelling.

Extra-oral examination revealed a diffuse, non-tender, firm swelling in the mid-face region approximately $5 \mathrm{~cm} \mathrm{X} 3 \mathrm{~cm}$ in size, extending superoinferiorly $1.5 \mathrm{~cm}$ from the infraorbital ridge to $2 \mathrm{~cm}$ above the inferior border of the mandible and anteroposteriorly $1 \mathrm{~cm}$ from the left corner of the mouth to $2.5 \mathrm{~cm}$ anterior to the tragus (figure 1). There was no local rise in temperature or change in color of the overlying skin. Lymph nodes were not palpable.

Intra oral examination showed ovoid swelling of about $5 \mathrm{~cm} \times 3 \mathrm{~cm}$. extending anteroposteriorly from left maxillary second premolar till tuberosity of the same side. Buccal vestibule appeared obliterated. The swelling was firm, non-fluctuant and pale pink in colour with smooth surface. There was no bleeding or pus discharge from the lesion (figure 2).

Radiographically, it appeared to be a large osteolytic lesion involving the left posterior maxilla extending from the alveolus to the infraorbital margin and from nasal septum to the zygomatic arch. The lesion had a mixed density with calcified mass seen within the radiolucency. The margins were relatively well defined. 27 was displaced in the left maxillary sinus, whereas, 28 appeared to be floating in space. Displacement of adjacent teeth was also evident (figure 3 ).

Histopathological examination of an incisional biopsy revealed loosely arranged stellate, spindleshaped, rounded and angular cells in an abundant loose myxoid stroma, relatively avascular containing few collagen fibrils. Inconspicuous island of odontogenic epithelium was also seen (figure 4). Stellate tumor cells showed anastomosing, long tapering, cytoplasmic processes (figure 5). On the basis of clinical, radiographical and histopathological features, diagnosis of "Odontogenic Myxoma" was made. 


\section{Discussion}

Myxoma is Latin word originates from the Greek word 'muxa', which means 'mucous'. There is a great controversy about the origin of myxomatous tumors. Bryant, in 1802, introduced the term myxosarcoma, which he described as a mucous transformation of round cell sarcoma, malignant and of large volume, usually attacking the omentum and skin. Furthermore, myxomas were described under the name of collenemas by Johannes Miller in $1838 .^{7}$ In an article titled cellularpathologie, German pathologist Rudolph Virchow (1863) coined term the 'myxoma' for a group of tumors that had histologic resemblance to the mucinous substance of the umbilical cord. ${ }^{8}$ In 1947, Thoma and Goldman were the first to mention myxomas of the jaws. ${ }^{9}$

The prevalence is principally quoted between $0.04 \%$ and $3.7 \%{ }^{10}$ On the basis of prospective study carried out in Tanzania, an annual incidence of 0.07 per million has been ascertained. ${ }^{11}$

The classification of Odontogenic Myxoma as an odontogenic tumor has been justified by its (1) almost exclusive occurrence in the tooth-bearing areas of the jaws, (2) its frequent occurrence in young individuals, (3) its common association with an unerupted tooth or a developmentally absent tooth, (4) its histologic resemblance to the primitive mesenchymal portion of the developing tooth germ (dental follicle, dental papilla, periodontal ligament), (5) the occasional presence of sparse amounts odontogenic epithelium. ${ }^{10}$ Adekeye et al, however, expressed the view that the frequency and significance of these features may have been overstated. The authors supposed that the rarity of OMs in any extragnathic bone could be the only firm reason for suggesting an odontogenic origin. ${ }^{9}$

Recently, Miyagi et al analyzed the expression of two proteins related to OM invasiveness (MMP-2 and hyaluronic acid) in human immature dental pulp stem cells and their results strongly suggested that dental pulp stem cells can be the precursors of OM. ${ }^{12}$

OMs are slow-growing, painless, and site-aggressive tumors. Growth may be rapid and infiltration of neighboring soft tissues structures may occur. Since pain and hypoesthesia are not common, the lesions may reach a considerable size before patient perceives its existence and seeks treatment. Larger lesions may cause tooth displacement and cortical bone expansion ${ }^{13}$, as seen in our patient.

When the maxillary sinus is involved, OM often fills the antrum. In severe cases, nasal obstruction or exophthalmus may be the leading symptoms. Association with unerupted teeth has been reported in only $5 \%$ of OM cases reviewed. No specific predilection for any ethnic group has been reported. ${ }^{14}$

The tumor usually occurs in 2 nd to 4 th decades of life and male to female ratio is $1: 1.5^{15}$, although cases in 3 month baby and 64 years old patients have also been reported. ${ }^{11}$ The occurrence of OM in the maxilla is rare when compared to the mandible (1:2). Farman et al. suggested that the mean age at the time of diagnosis of maxillary odontogenic myxomas in men was 29.2 years and in women was 35.3 years, while the mandibular odontogenic myxomas in men occur at a mean age of 25.8 years and in women at 29.3 years. ${ }^{16}$ Our case involved a 24 year old female with a large lesion of the left maxilla infiltrating the maxillary sinus of the same side.

Radiological diagnosis of odontogenic myxoma is difficult because of overlapping features with other benign and malignant bone lesions. Appearance of lesion may vary from a unilocular radiolucency to a multicystic lesion with well-defined or diffused margins with fine, bony trabeculae within its interior structure expressing a "honey coumbed," "soap bubble," or "tennis racket" appearance. A unilocular appearance may be seen more commonly in children and in anterior parts of the jaws. ${ }^{17,18}$

Zhang $\mathrm{J}$ et al in 2007 divided radiographical findings of OMs into six types: Type I-unilocular; Type II-multilocular (including honeycomb, soap bubble and tennis racquet patterns); Type III-involvement of local alveolar bone; Type IV-involvement of the maxillary sinus; Type V-osteolytic destruction and Type VI-a mix of osteolytic destruction and osteogenesis. ${ }^{19}$ A study done by Naffke CE, et al. on odontogenic myxoma revealed tennis racket appearance to be the most common radiographic finding. ${ }^{20}$

Because of mixed radiopaque-radiolucent appearance, ascribed to the presence of foci of calcification, the diagnosis should be considered in mixed radiolucent-radiopaque lesions.

Macroscopically, OM has a whitish, translucent, mucinous appearance. It is un-encapsulated and poorly demarcated, thus permeating the surrounding bone and soft tissue by expansion rather than as a result of cellular growth. ${ }^{21}$

Microscopically, odontogenic myxomas are composed of loosely arranged, evenly distributed spindleshaped, rounded, and stellate cells with a lightly eosinophilic cytoplasm in a mucoid-rich (myxoid) intercellular matrix. Many stellate tumor cells have anastomizing, long tapering cytoplasmic processes. Cellular and nuclear polymorphism is rare as is mitotic activity. The tumor is relatively avascular or may exhibit delicate capillaries. Remnants of odontogenic epithelium may or may not present. ${ }^{9,22,23}$ The histopathological examination in the present case showed presence of loose, spindle, rounded, stellate cells with long branching cytoplasmic processes in loose myxoid stroma.

OM has to be differentiated from other pathologies with similar histologic presentations like myxoid neurofibroma, myxoid liposarcoma, myxoid chondrosarcoma by enzymatic reactions (these being low in 
alkaline phosphatase and lactate dehydrogenase activity and high acid phosphatase, G6Pase dehydrogenase and isocitrate dehydrogenase activity while the reverse is true for odontogenic myxoma) ${ }^{24}$

Farman et al (1977) histochemical findings of ground substance of OMs showed to consists of about $80 \%$ hyaluronic acid and $20 \%$ chondroitin sulphate. ${ }^{14,22}$ García-Muñoz et al., stated that orosomucoid protein is immunomodulatory and angiogenic and therefore results in invasive behavior of OM. It is anti-inflammatory, anti-neutrophil, anti-complement. Presence of orosomucoid protein justifies classical mucoid appearance of the tumor. ${ }^{7}$

Odontogenic myxosarcoma, malignant variant of $\mathrm{OM}$ is exceedingly rare. It is a controversial issue, and several authors have addressed it. Many of these cases have had a malignant histologic appearance or exhibited an aggressive clinical course with death by local extension but without documented metastases. Lamberg MA et al reported findings on a maxillary myxoma in which histologic and cytogenetic findings supported a malignant interpretation. ${ }^{25}$

The tumor is not radiosensitive. Hence, surgical excision is the recommended treatment ranging from conservative curettage to radical excision. Owing to its potential for local infiltration, simple enucleation and curettage alone have been associated with a high recurrence rate of $10 \%$ to $33 \%$. Thus, radical excision with burring of the cavity borders with a drill should be performed with maximum preservation of surrounding structures. ${ }^{26}$

\section{Conclusion}

Myxoma is one of the least common lesions of maxillary bone, representing 3 to $8 \%$ of odontogenic tumors and cysts. The dental origin cannot be absolutely validated but is most probable as these tumors are almost exclusive to facial skeleton and universally absent in other bones of the skeleton. Our case underlines the difficulty in establishing a correct diagnosis, which requires interaction between radiologist, surgeon and pathologist.

\section{References:}

[1]. Spencer K R. Odontogenic myxoma: Case report with reconstructive considerations. Australian Dental Journal 1998;43:(4):000000 .

[2]. Rani V, Masthan K, Kadar M, Babu A, Sankari L, Krishnasamy G. Odontogenic myxoma diagnostic dilemma: A case report and review of literature. J Cranio Max Dis. 2014;3:163-7.

[3]. Leiser Y, Abu-El-Naaj I, Peled M. Journal of Cranio-Maxillofacial Surgery. 2009;37:206-209.

[4]. Altug H A, Gulses A, Sencimen M. Clinico-radiographic examination of odontogenic myxoma with displacement of unerupted upper third molar: review of the literature. Int. J. Morphol. 2011;29(3):930-933.

[5]. Friedrich RE, Scheuer HA, Fuhrmann A, Zustin J, Assaf AT. Radiographic findings of odontogenic myxomas on conventional radiographs. Anticancer Res. 2012 May;32(5):2173-7.

[6]. Miyagi SP, Hiraki KR, Martins MD, Marques MM. Expression of matrix metalloproteinases 2 and 9 in odontogenic myxoma in vivo and in vitro. J Oral Sci. 2008 Jun;50(2):187-92.

[7]. Sarkar RR. Oncologic profile of maxillary odontogenic myxoma: A rare case. Contemp Clin Dent. 2013;4:374-7.

[8]. de Melo AUC, de Farias Martorelli SB, de Holanda Cavalcanti PH, Gueiros LA, de Oliveira Martorelli F. Maxillary odontogenic myxoma involving the maxillary sinus - Case report. Rev. Bras. Otorrinolaringol. 2008;74(3):472-75.

[9]. Reichart PA, Philipsen HP. Benign neoplasms and tumor like lesions showing mesenchyme and/or ectomesenchyme. Odontogenic tumors and allied lesions. Quintessence Publishing Co. Ltd. London. 2004.p-189.

[10]. Brannon RB. Odontogenic tumors. Oral Maxillofaial Surg Clin N Am. 2004;16:359-374. Brannon RB. Central odontogenic fibroma, myxoma (odontogenic myxoma, fibromyxoma) and central odontogenic granular cell tumour. Oral Maxillofac Surg Clin North. Am. 2004;16(3):359-374.

[11]. Simon EN, Merkx M, Vuhahula E, Ngassapa D, Stoelinga PJ. Odontogenic myxoma: a clinicopathological study of 33 cases. Int J Oral Maxillofac Surg. 2004 Jun;33(4):333-7.

[12]. Miyagi SPH, Maranduba CMDC, Silva FD, Marques MM. Dental pulp stem cells express proteins involved in the local invasiveness of odontogenic myxoma. Braz. oral res. 2012;26(2):139-44.

[13]. Manne RK, Kumar VS, Sarath PV, Anumula L, Mundlapudi S, Tanikonda R. Odontogenic Myxoma of the Mandible. Hindawi Publishing Corporation Case Reports in Dentistry. 2012:1-4.

[14]. Singaraju S, Wanjari SP, Parwan RN. Odontogenic myxomas of jaw. JOMFP. 2010 14(1):19-23.

[15]. Kaffe I, Naor H, Buchner A. Clinical and radiological features of odontogenic myxoma of the jaws. Dentomaxillofac Radiol. 1997;26(5):299-303.

[16]. Sharma N, Prashant D, Sharma S, Prashant V. Odontogenic Myxoma of Oral Cavity: A Case Report. International Journal of Oral \& Maxillofacial Pathology. 2013:4(1):85-89.

[17]. Sivakumar G, Kavitha B, Saraswathi TR, Sivapathasundharam B. Odontogenic myxoma of maxilla. IJDR. 2008;19(1):62-65.

[18]. Shah A, Lone P, Latoo S, Ahmed I, Malik A, Hassan S et al. Odontogenic myxoma of the maxilla: A report of a rare case and review on histogenetic and diagnostic concepts. Natl J M axillofac Surg. 2011;2:189-9.

[19]. Zhang J, Wang H, He X, Niu Y, Li X. Radiographic examination of 41 cases of odontogenic myxomas on the basis of conventional radiographs. Dentomaxillofac Radiol. 2007 Mar;36(3):160-7.

[20]. Noffke CE, Raubenheimer EJ, Chabikuli NJ, Bouckaert MMR. Odontogenic myxoma: review of the literature and report of 30 cases from South Africa. OOOE. 2007;104(1):101-9.

[21]. Rius JM, Nadal A, Lahor E, Mtui B, Brunet L. Unusual presentation of localized gingival enlargement associated with a slowgrowing odontogenic myxoma. International Journal of Oral Science (2013) 5, 172-175

[22]. Rajendran R, Sivapathasundram B. Sahfer's Textbook of Oral Pathology. $7^{\text {th }}$ ed. Elsevier India Private Limited. Gurgaon. 2012.p299. 
[23]. Reddy SP, Naag A, Bina Kashyap. Odontogenic myxoma: Report of two cases. Natl J Maxillofac Surg. 2010 Jul-Dec; 1(2): 183186.

[24]. Newaskar V, Agrawal D, Shrivastava S, Shakya N. Aggressive myxoma in a pediatric patient-a case report. IJRID. 2013;3(2):40-49

[25]. Lamberg MA, Calonius BP, Mäkinen JE, Paavolainen MP, Syrjänen KJ et al. A case of malignant myxoma (myxosarcoma) of the maxilla. Scand J Dent. 1984 Aug;92(4):352-7.

[26]. Munjal M, Bhardwaj V, Garg B, Sood. N Odontogenic Myxoma Of The Maxilla: A Clinical Case Report And Review Of Literature. Otolarynology. 2013;3(2):51-60.

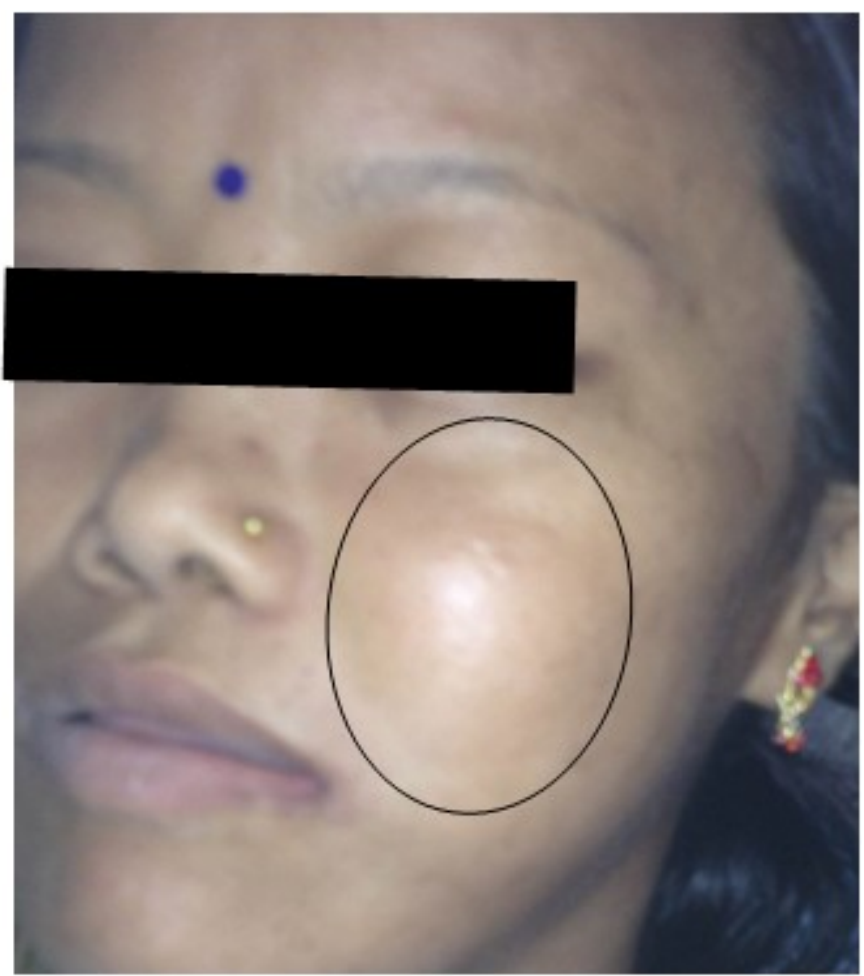

Fig 1: Showing extra oral swelling

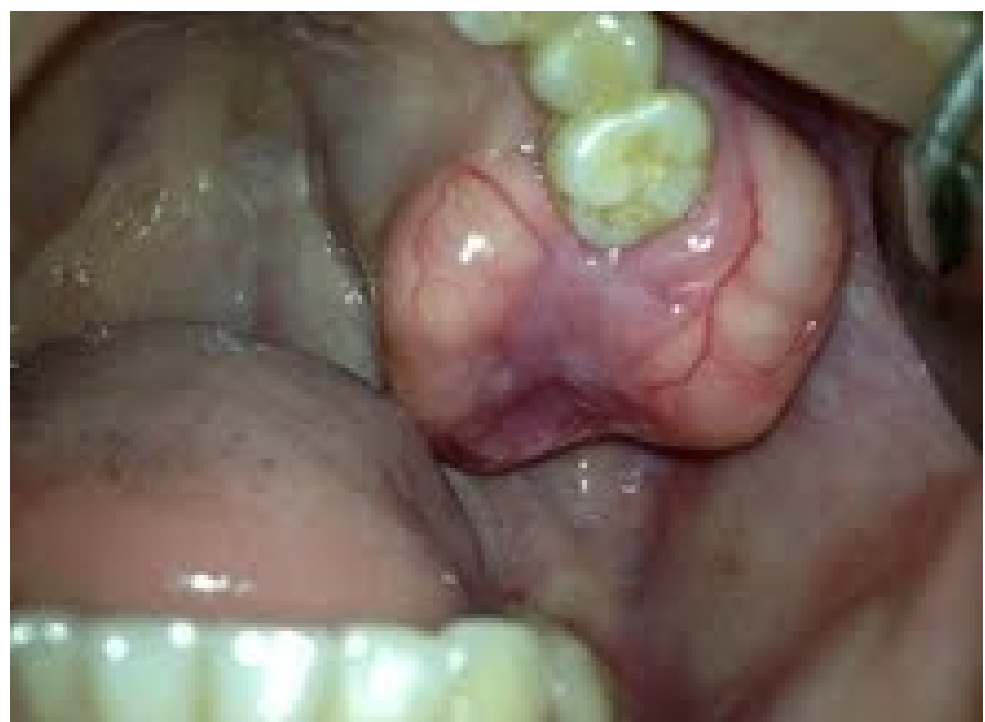

Fig 2: Showing intaroral swelling 


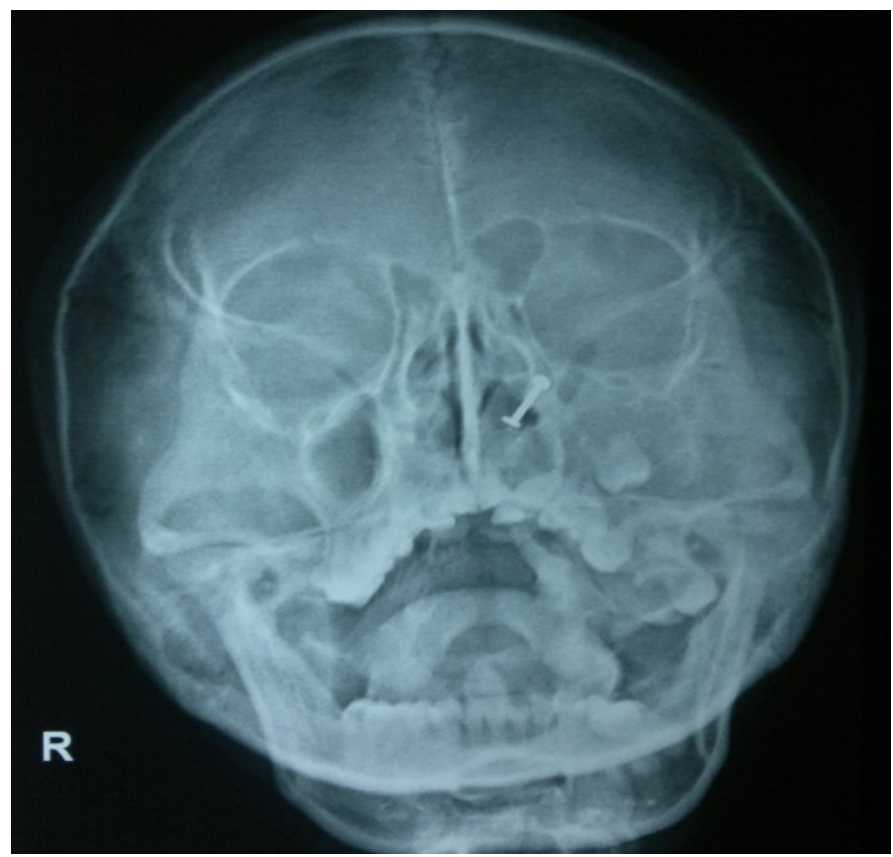

Fig 3: PNS view showing maxillary sinus infiltration with displaced teeth

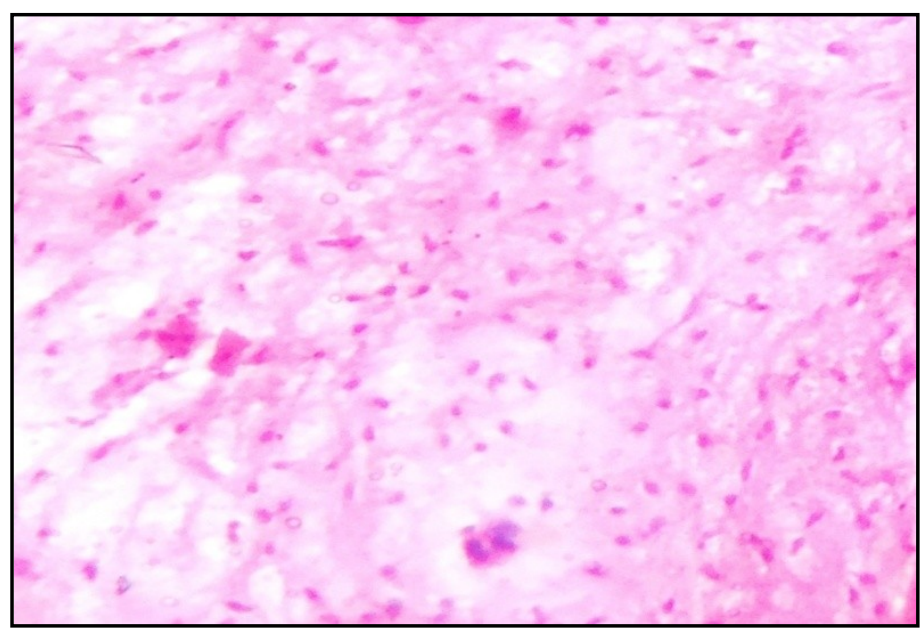

Fig 4: Photograph shows collection of stellate, spindle-shaped, rounded and angular fibroblasts cells in an abundant loose myxoid stroma, with inconspicuous strands of odontogenic epithelium in a myxoid stroma; $\mathrm{H} \& \mathrm{E}(\mathrm{x} 100)$.

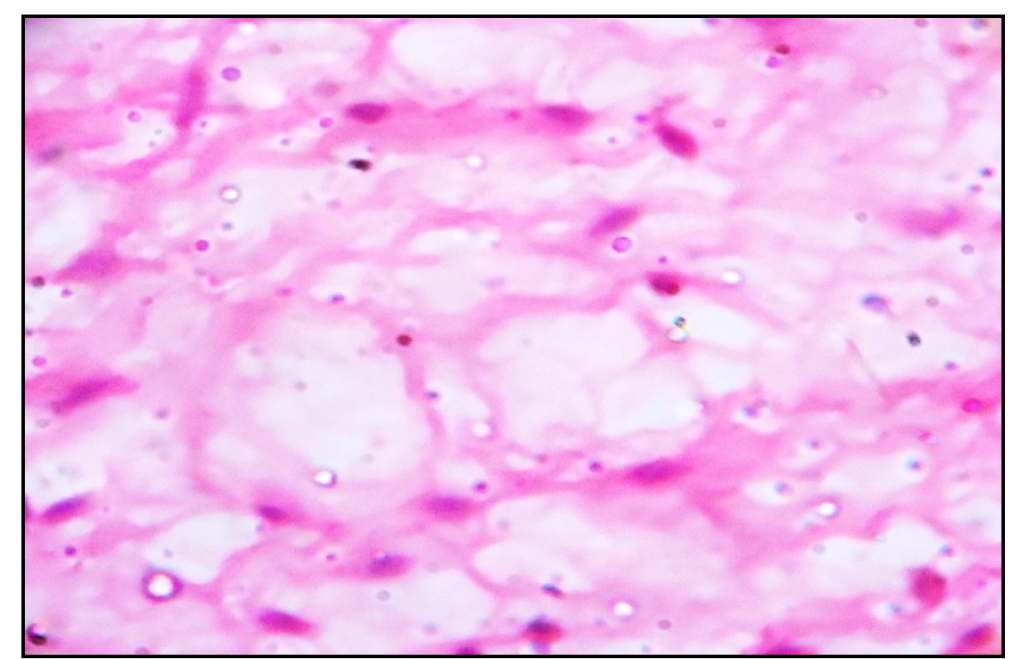

Fig 5: Stellate tumor cells showing anastomozing, long tapering, cytoplasmic processes; $H \& E(x 400)$. 